\title{
Traffic exposure and lung function in adults: the Atherosclerosis Risk in Communities study
}

\author{
Haidong Kan, Gerardo Heiss, Kathryn M Rose, Eric Whitsel, Fred Lurmann, Stephanie J London
}

Thorax 2007;62:873-879. doi: 10.1136/thx.2006.073015

See end of article for authors' affiliations

......................

Correspondence to: Dr Stephanie J London, National Institute of Environmental Health Sciences, P O Box 12233 Research Triangle Park, North Carolina 27709, USA; london2@niehs.nih. gov

Received 9 October 2006 Accepted 31 March 2007 Published Online First 18 April 2007
Background: Traffic exposure is a major contributor to ambient air pollution for people living close to busy roads. The relationship between traffic exposure and lung function remains inconclusive in adults.

Methods: A cross-sectional study was conducted to investigate the association between traffic exposure and lung function in the Atherosclerosis Risk in Communities (ARIC) study, a community based cohort of 15792 middle aged men and women. Traffic density and distance to major roads were used as measures of traffic exposure.

Results: After controlling for potential confounders including demographic factors, personal and neighbourhood level socioeconomic characteristics, cigarette smoking and background air pollution, higher traffic density was significantly associated with lower forced expiratory volume in $1 \mathrm{~s}\left(\mathrm{FEV}_{1}\right)$ and forced vital capacity (FVC) in women. Relative to the lowest quartile of traffic density, the adjusted differences across increasing quartiles were $5.1,-15.4$ and $-21.5 \mathrm{ml}$ for $\mathrm{FEV}_{1}(\mathrm{p}$ value of linear trend across the quartiles $=0.041$ ) and $1.2,-23.4$ and $-34.8 \mathrm{ml}$ for $\mathrm{FVC}$ ( $p$ trend $=0.010$ ). Using distance from major roads as a simpler index of traffic related air pollution exposure, the $\mathrm{FEV}_{1}$ was $-15.7 \mathrm{ml}(95 \% \mathrm{Cl}-34.4$ to 2.9$)$ lower and the $\mathrm{FVC}$ was $-24.2 \mathrm{ml}(95 \% \mathrm{Cl}-46.2$ to -2.3$)$ lower for women living within $150 \mathrm{~m}$ compared with subjects living further away. There was no significant effect of traffic density or distance to major roads on lung function in men. The $\mathrm{FEV}_{1} / \mathrm{FVC}$ ratio was not significantly associated with traffic exposure in either men or women.

Conclusions: This is the largest published study of traffic exposure and pulmonary function in adults to date. These results add to growing evidence that chronic exposure to traffic related air pollution may adversely affect respiratory health.
$\mathrm{R}$ oad traffic is a major factor in ambient air pollution in industrialised countries, contributing pollutants including fine particulate matter, carbon monoxide and oxides of nitrogen. An expanding body of epidemiological research suggests that traffic related exposure is associated with acute and chronic respiratory effects. ${ }^{1-7}$ For example, residential proximity to busy roads is associated with a variety of adverse respiratory health outcomes including symptoms ${ }^{1-3}$ and asthma exacerbation. ${ }^{4-7}$ The effect of traffic air pollution on adult lung function remains inconclusive; exposure to automobile exhaust was associated with lower lung function in adults in some studies $^{8-12}$ but not others. ${ }^{13} 14$

Traffic emissions result in small scale spatial variations and higher concentrations within short distances from major roads. ${ }^{15}{ }^{16}$ Air pollution data from fixed monitoring stations may be inadequate to study traffic related air pollution and health outcomes, especially for those living near busy roads. For example, Hoek and colleagues identified a consistent association between cardiopulmonary mortality and living near a major road, but not with estimated ambient background concentration of the traffic indicator pollutants black smoke and nitrogen dioxide. ${ }^{17}$ Assessment of traffic exposure can enhance studies of health effects of ambient air pollution because local sources are important, and because few people live close to the monitoring stations which are purposefully located away from local sources like busy roads. For people living close to busy roads, air pollution from traffic sources may be more important than the area background measured at the closest monitoring station.

We examined the relation between traffic exposure and lung function in a population based cohort of 15792 middle-aged men and women, the Atherosclerosis Risk in Communities (ARIC) study.

\section{METHODS}

Study population

Participants were from the ARIC study which is designed to investigate the natural history and aetiology of atherosclerosis and its sequelae. The design, objectives and quality control activities of the ARIC study have been reported in detail elsewhere. ${ }^{18} 19$ Participants were sampled from four US communities: Forsyth County, North Carolina; Jackson, Mississippi; northwest suburbs of Minneapolis, Minnesota; and Washington County, Maryland. The lung function variables collected during visit 1 (1987-9) were used with the traffic and background air pollution data in a cross-sectional analysis. Participants of an ethnicity other than African American or white were excluded from the current analysis $(\mathrm{n}=48)$. Also, African-Americans from Minnesota and Maryland field centres were excluded $(n=55)$ because of their small number.

We also repeated this analysis using visit 2 (1990-2) and conducted a longitudinal analysis on the change in lung function between visit 1 and visit 2 .

\section{Pulmonary function measurements}

The main measurements of lung function were forced expiratory volume in $1 \mathrm{~s}\left(\mathrm{FEV}_{1}\right)$, volume of gas (in litres) exhaled in the first second of expiration; forced vital capacity (FVC), total volume of gas exhaled; and the ratio of $\mathrm{FEV}_{1} / \mathrm{FVC}$.

Abbreviations: ARIC, Atherosclerosis Risk in Communities; BMI, body mass index; ETS, environmental tobacco smoke; $F_{E V}$, forced expiratory volume in $1 \mathrm{~s}$; FVC, forced vital capacity; GIS, geographical information system; $\mathrm{PM}_{10}$, particulate matter $<10 \mu \mathrm{m}$ 
Quality control was carefully conducted throughout the study, as described previously. ${ }^{20}$

\section{Geocoding}

Participant addresses were geocoded using a commercial service (Mapping Analytics LLC, Rochester, New York, USA) which assigned a latitude and longitude coordinate to each address. This geocoding was performed with the Centrus Enhanced Database which was primarily based on the Topologically Integrated Geographic Encoding and Referencing system (TIGER) data. Visit 1 addresses for 13972 participants $(88.4 \%)$ were successfully geocoded.

\section{Traffic exposure}

We quantified small scale spatial variations in traffic exposure by two measurements: geographical information system (GIS) mapped traffic density assignments at residences, and the distance of residences to nearest roadways of four typesinterstate highways (road class 1), state highways (road class 2 ), major arterial roads (road class 3 ) and local roads (road class 4$)$.

\section{Traffic density}

Traffic density data were generated using a decay function that approximates the potential influence of activity weighted mobile source emissions at various distances from a roadway. This method accounts for the combined relative influence of several roadways (and road types) with various traffic activity levels at different distances from each residence location. The metric generally behaves like an inverse distance weighted traffic volume, except that it specifically considers intersections and multiple roadways more accurately. These density values therefore give a relative indication of which residence locations are likely to be most exposed to traffic activity and, as such, are dimensionless indicators of proximity to traffic volume.

Because the available traffic density data were from 2000, we back extrapolated to the study period (1987-92) based on change in population density using county level census population data. Changes in traffic volumes over time are correlated with changes in population density. ${ }^{21}$

\section{Distance to major roads}

To estimate qualitatively the distribution of the distance from residence locations to roadways, straight line distances were calculated. The distance to roadway data include the distance (in metres) from each unique residence location to the nearest roadway for the four road classes. Given inherent imprecision in geocoding and assessment of distances to roads, minimums were set to $30 \mathrm{~m}$ for class 1 roads, $20 \mathrm{~m}$ for class 2 roads, $10 \mathrm{~m}$ for class 3 roads and $10 \mathrm{~m}$ for class 4 roads.

Consistent with previous literature,,$^{22-24}$ we dichotomised distance to major roads (interstate and state highways, major arterials) at $150 \mathrm{~m}$. In addition, we conducted a sensitivity analysis and categorised distance to major roads as $<100 \mathrm{~m}$ and $\geqslant 100 \mathrm{~m}^{12}$

\section{Background air pollution level}

Data on the background ambient concentrations of particulate matter $<10 \mu \mathrm{m}\left(\mathrm{PM}_{10}\right)$, nitrogen dioxide and ozone during the research period were acquired from the Environmental Protection Agency air quality data retrieval system. We abstracted $24 \mathrm{~h}$ average concentrations of $\mathrm{PM}_{10}$ and nitrogen dioxide and $8 \mathrm{~h}(10.00$ to $18.00 \mathrm{~h})$ average concentrations for ozone. The average concentrations during our research period (1987-92) were spatially interpolated from air quality monitoring stations to the cohort residence locations using inverse distance weighting.

\section{Other covariates}

Anthropometric measures were determined by trained certified technicians following a standardised protocol. Interviewers collected information on age, ethnicity, sex, smoking, environmental tobacco smoke (ETS) exposure, occupation, education, medical history and other factors.

Neighbourhood level socioeconomic factors, in addition to individual level factors, may have an impact on health status. ${ }^{25}$ We therefore included 1990 census tract level data on median household income, median vehicle number per housing unit, employment rate and poverty rate. ${ }^{26}$

\section{Statistical analysis}

Distributions of traffic density are highly skewed (see fig 1, drawn in SPSS Version 11.0, Chicago, Illinois, USA) so we analysed traffic density in quartiles. SAS Version 9.1.2 (Cary, North Carolina, USA) software was used for statistical analyses. Based on previous literature, potential confounding factors including research centre, ethnicity, age, smoking status (never, former and current) and pack years, ETS, body mass index (BMI), occupation, educational level, height, square of height, census tract socioeconomic factors (median household income, median vehicle number per housing unit, employment rate, and poverty rate) and background air pollution level were included in the analysis. The square of height was used because it explained more variation in lung function measurements than height. ${ }^{27}$ BMI and pack years were treated as quintiles given their non-linear relationships with $\mathrm{FEV}_{1}$ and FVC. When jointly modelling individual and census tract level measures, hierarchical regression (SAS PROC MIXED) was employed as it provides variance estimates which have been adjusted to take into account the dependence of measures from the same areas. Factors potentially modifying the exposure to traffic (sex, smoking and ethnicity) were evaluated for possible inclusion as interaction terms with traffic exposure.

\section{RESULTS \\ Participant description}

Table 1 shows selected characteristics of the participants at baseline, overall and by sex. The mean age of the participants was 54.2 years. Compared with men, women were slightly younger, less likely to smoke, more likely to be African Americans and had a slightly higher BMI.

Subjects in the highest quartile of traffic density and those living closest to major roads were slightly older, had slightly higher BMI values and were more likely to be current smokers (tables A2 and A3 in the appendix available online at http:// thorax.bmj.com/supplemental). Those living closer to main roads $(<150 \mathrm{~m})$ had resided in lower neighbourhood socioeconomic areas. Patterns were similar in men and women.

The estimated traffic density and background air pollutant $\left(\mathrm{PM}_{10}\right.$, nitrogen dioxide and ozone) concentrations at the visit 1 home address varied greatly among participants (fig 1). Consistent with previous reports, ${ }^{28}$ we did not find a strong correlation between traffic density and background air pollution level; the Pearson correlation coefficients of traffic density with $\mathrm{PM}_{10}$, nitrogen dioxide and ozone were $-0.12,-0.04$ and -0.10 , respectively.

Table 2 shows the distributions of the estimated distances from the home address at visit 1 to four types of roads; 5444 (39.0\%) participants lived within $150 \mathrm{~m}$ of major roads (road classes 1-3) and only 264 (1.9\%) participants lived within $150 \mathrm{~m}$ of an interstate highway. 

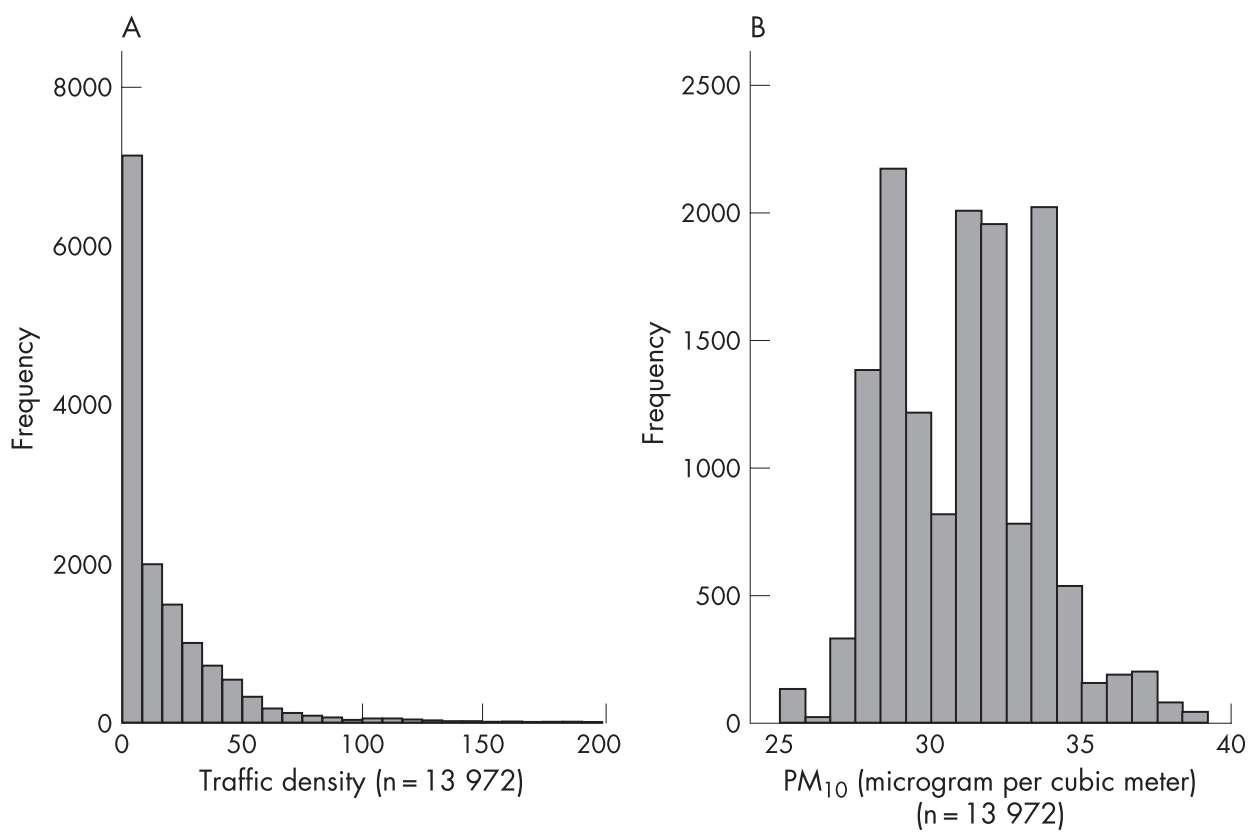

Figure 1 Distribution of traffic density and background air pollutant concentrations at residences of participants in the Atherosclerosis Risk in Communities (ARIC) study, 1987-9. (A) Traffic density;

(B) particulate matter $<10 \mu \mathrm{m}\left(\mathrm{PM}_{10}\right)$;

(C) nitrogen dioxide $\left(\mathrm{NO}_{2}\right)$; (D) ozone $\left(\mathrm{O}_{3}\right)$.
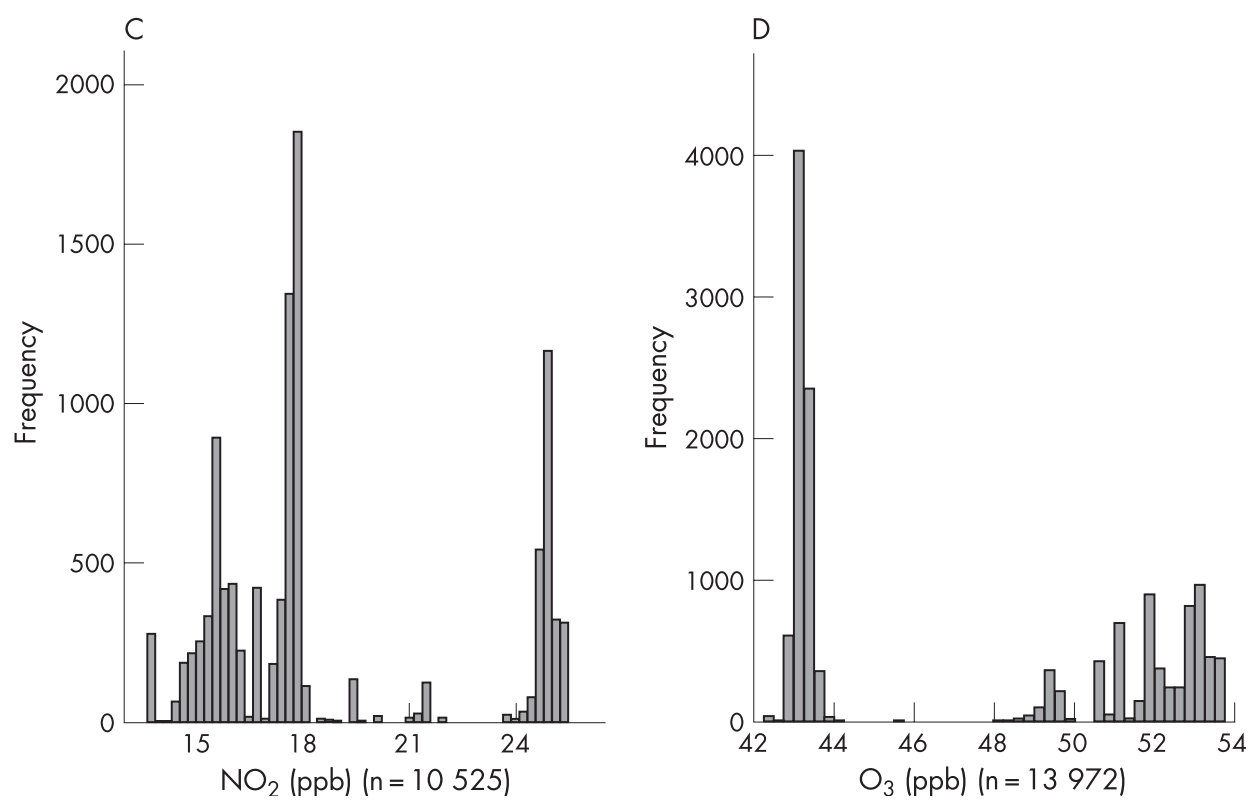

Table 1 Selected baseline demographic characteristics of the ARIC participants (1987-9)*

\begin{tabular}{|c|c|c|c|}
\hline & $\begin{array}{l}\text { Total } \\
\text { (n=13 972) }\end{array}$ & $\begin{array}{l}\text { Women } \\
(n=7789)\end{array}$ & $\begin{array}{l}\text { Men } \\
(n=6183)\end{array}$ \\
\hline Age (years) & $54.2(5.8)$ & $53.8(5.7)$ & $54.6(5.8)$ \\
\hline \multicolumn{4}{|l|}{ Smoking status } \\
\hline Current smoker (\%) & 26.2 & 24.8 & 28.0 \\
\hline Former smoker (\%) & 32.3 & 22.7 & 44.3 \\
\hline Never smoker (\%) & 41.5 & 52.5 & 27.7 \\
\hline \multicolumn{4}{|l|}{ Ethnicity } \\
\hline Black (\%) & 28.4 & 31.8 & 24.1 \\
\hline White (\%) & 71.6 & 68.2 & 75.9 \\
\hline BMI $\left(\mathrm{kg} / \mathrm{m}^{2}\right)$ & $27.7(5.4)$ & $27.9(6.2)$ & $27.5(4.2)$ \\
\hline Height $(\mathrm{cm})$ & $168.5(9.3)$ & $162.4(6.0)$ & $176.2(6.6)$ \\
\hline $\mathrm{FEV}_{1}$ (I) & $2.8(0.8)$ & $2.4(0.5)$ & $3.3(0.7)$ \\
\hline FVC (I) & $3.8(1.0)$ & $3.2(0.6)$ & $4.5(0.9)$ \\
\hline $\mathrm{FEV}_{1} / \mathrm{FVC}$ ratio (\%) & $74.5(8.1)$ & 75.6 (7.4) & $73.1(8.6)$ \\
\hline
\end{tabular}

$\mathrm{BMI}$, body mass index; $\mathrm{FEV}_{1}$, forced expiratory volume in $1 \mathrm{~s}$; FVC, forced vital capacity. ${ }^{*}$ All values are mean (SD) unless specified as percentages. 
Table 2 Distributions of distance to different classes of roads at ARIC participant residences (in metres, $n=13972$ )*

\begin{tabular}{lrllllrr}
\hline & Mean & SD & Minimum & P25 & Median & P75 & Maximum \\
\hline Distance to class 1 roads & 2207 & 2008 & 30 & 896 & 1795 & 2774 & 17053 \\
Distance to class 2 roads & 2755 & 2573 & 20 & 923 & 2254 & 3593 & 22382 \\
Distance to class 3 roads & 363 & 502 & 10 & 103 & 230 & 427 & 5389 \\
Distance to class 4 roads & 29 & 42 & 10 & 10 & 18 & 31 & 833 \\
\hline
\end{tabular}

P25 and P75, 25th and 75th percentile.

*Interstate highways (class 1), state highways (class 2), major arterials (class 3) and local roads (class 4).

\section{Traffic exposure and lung function}

Because we observed a significant interaction between sex and traffic density for FVC $(p=0.041)$, the relationships between measures of traffic exposure and lung function are presented using sex-specific multivariate regression.

Both before and after adjustment for confounders, an inverse relation was found between lung function and traffic density among women (table 3). Relative to the lowest quartile of traffic density, the adjusted differences across increasing quartiles were $5.1,-15.4$ and $-21.5 \mathrm{ml}$ for $\mathrm{FEV}_{1}$, and 1.2, -23.4 and $-34.8 \mathrm{ml}$ for FVC. This linear trend was significant for both $\mathrm{FEV}_{1}(\mathrm{p}=0.041)$ and FVC $(\mathrm{p}=0.010)$. We did not find a clear association between traffic density and $\mathrm{FEV}_{1}$ or FVC in men (table 4).

A similar pattern, although of lower statistical significance, was seen for living near major roads. Among women living within $150 \mathrm{~m}$ of a major road, the $\mathrm{FEV}_{1}$ was $-15.7 \mathrm{ml}$ (95\% CI -34.4 to 2.9 ) lower and the FVC was $-24.2 \mathrm{ml}$ (95\% CI -46.2 to -2.3 ) lower in multivariate analyses compared with women living further away (table 5). In a sensitivity analysis using different cut off points ( $\geqslant 100 \mathrm{~m}$ and $<100 \mathrm{~m})$, similar but weaker patterns were found in women (table 5). We did not observe significant effects of distance in men.

The ratio of $\mathrm{FEV}_{1} / \mathrm{FVC}$ was not significantly associated with traffic density or distance to major roads in either sex (tables 3$5)$.

We did not observe significant effect modification of the association between traffic density and lung function by smoking ( $\mathrm{p}=0.989$ for $\mathrm{FEV}_{1}$ and 0.867 for $\mathrm{FVC}$ ) or ethnicity $\left(p=0.371\right.$ for $\mathrm{FEV}_{1}$ and 0.147 for FVC $)$.

When the analyses were repeated using traffic exposure and lung function data obtained at visit 2 , the associations were generally similar to those described for visit 1 (see tables A7 and A8 in the online appendix available at http://thorax.bmj.com/ supplemental).

Given the small effect of traffic in our study and earlier publications $^{8-12}$ and because we had only two pulmonary function measurements spaced 3 years apart, we did not anticipate being able to detect an effect of traffic on change in pulmonary function. Nonetheless, we performed supplementary longitudinal analyses. No significant associations were found (see tables A9 and A10 in the online appendix available at http://thorax.bmj.com/supplemental).

\section{DISCUSSION}

This study provides evidence that lung function, as measured by $\mathrm{FEV}_{1}$ and $\mathrm{FVC}$, is reduced in adults exposed to higher levels of traffic, especially among women. To our knowledge, this is the first population-based study in the USA and the largest one to date in the world to investigate the relation between measured traffic exposure and lung function in adults. The magnitude of the observed association between traffic exposure and lung function was similar to reported effects of outdoor air pollution ${ }^{29}$ and smaller than effects of personal smoking ${ }^{30}$ or ETS exposure. ${ }^{31}$

As in some other studies, ${ }^{32-36}$ we did not find a significant association between the $\mathrm{FEV}_{1} / \mathrm{FVC}$ ratio and measures of traffic exposure. This suggests that the traffic related reduction in $\mathrm{FEV}_{1}$ and FVC was probably due to loss of lung volume (restriction) rather than airflow obstruction. Of course, a reduced FVC in the presence of a normal $\mathrm{FEV}_{1} / \mathrm{FVC}$ can be used to suggest-but not to diagnose-the presence of a restrictive abnormality. ${ }^{37}$

There are relatively few published studies of traffic related air pollution and lung function in either children or adults. In the Netherlands, investigators found that exposure to traffic related air pollution, especially diesel exhaust particles, was associated with reduced lung function in children living near major motorways. ${ }^{38}$ A German study suggested that exposure to a pollution profile of heavy traffic and domestic heating was related to markedly lower FVC and FEV 1 in children. ${ }^{39}$ Several recent studies on traffic air pollution provide some support for our finding..$^{10-12}{ }^{14}$ An 8-year longitudinal study of 5682 women in Tokyo showed a larger decrease in $\mathrm{FEV}_{1}$ for participants with

Table 3 Associations between traffic density and $\mathrm{FEV}_{1}, \mathrm{FVC}$ and $\mathrm{FEV} / \mathrm{FVC}$ ratio in female ARIC participants (1987-9)

\begin{tabular}{|c|c|c|c|c|c|}
\hline & \multicolumn{4}{|c|}{ Quartiles of traffic density } & \multirow[b]{2}{*}{ p Valuet } \\
\hline & 1 (lowest) & 2 & 3 & 4 & \\
\hline \multicolumn{6}{|l|}{$\mathrm{FEV}_{1}(\mathrm{ml})$} \\
\hline Age adjusted model & 0 & $2.8(-28.6$ to 34.2$)$ & $-15.9(-47.1$ to 15.4$)$ & $-34.7(-66.2$ to -3.1$)$ & 0.011 \\
\hline Multivariate model* & 0 & $5.1(-21.7$ to 31.9$)$ & $-15.4(-42.3$ to 11.5$)$ & $-21.5(-48.5$ to 5.5$)$ & 0.041 \\
\hline \multicolumn{6}{|l|}{$\mathrm{FVC}(\mathrm{ml})$} \\
\hline Age adjusted model & 0 & $-5.9(-43.8$ to 32.1$)$ & $-26.0(-63.8$ to 11.8$)$ & $-47.1(-85.3$ to -8.9$)$ & 0.016 \\
\hline Multivariate model* & 0 & $1.2(-30.4$ to 32.7$)$ & $-23.4(-55.0$ to 8.2$)$ & $-34.8(-66.5$ to -3.1$)$ & 0.010 \\
\hline \multicolumn{6}{|l|}{$\mathrm{FEV}_{1} / \mathrm{FVC}(\%)$} \\
\hline Age adjusted model & 0 & $0.1(-0.4$ to 0.5$)$ & $-0.1(-0.6$ to 0.4$)$ & $-0.1(-0.6$ to 0.3$)$ & 0.276 \\
\hline Multivariate model* & 0 & $0.1(-0.4$ to 0.6$)$ & $0.0(-0.5$ to 0.5$)$ & $0.1(-0.4$ to 0.5$)$ & 0.911 \\
\hline
\end{tabular}

$\mathrm{FEV}_{1}$, forced expiratory volume in $1 \mathrm{~s}$; FVC, forced vital capacity.

*Adjusted for centre, ethnicity, age, smoking status, pack-years of cigarette smoking, environmental tobacco smoke, body mass index, occupation, educational level, census tract-based income, height, square of height and background air pollution level.

tp Values for trend based on quartiles scaled by quartile medians. 
Table 4 Associations between traffic density and $\mathrm{FEV}_{1}, \mathrm{FVC}$ and $\mathrm{FEV}_{1} / \mathrm{FVC}$ ratio in male ARIC participants (1987-9)

\begin{tabular}{|c|c|c|c|c|c|}
\hline & \multicolumn{4}{|c|}{ Quartiles of traffic density } & \multirow[b]{2}{*}{ p Valuet } \\
\hline & 1 (lowest) & 2 & 3 & 4 & \\
\hline \multicolumn{6}{|l|}{$\mathrm{FEV}_{1}(\mathrm{ml})$} \\
\hline Age adjusted model & 0 & 58.9 (5.9 to 111.8 ) & $19.2(-34.1$ to 72.5$)$ & $19.6(-34.9$ to 74.1$)$ & 0.664 \\
\hline Multivariate model ${ }^{*}$ & 0 & $21.2(-23.7$ to 66.0$)$ & $-11.2(-56.7$ to 34.2$)$ & $10.2(-35.9$ to 56.3$)$ & 0.994 \\
\hline \multicolumn{6}{|l|}{ FVC (ml) } \\
\hline Age adjusted model & 0 & $55.2(-6.6$ to 117.0$)$ & $13.2(-49.0$ to 75.5$)$ & $24.8(-38.9$ to 88.5$)$ & 0.956 \\
\hline Multivariate model* & 0 & $16.4(-34.0$ to 66.7$)$ & $-21.9(-73.0$ to 29.2$)$ & $11.7(-40.2$ to 63.5$)$ & 0.856 \\
\hline \multicolumn{6}{|l|}{$\mathrm{FEV}_{1} / \mathrm{FVC}(\%)$} \\
\hline Age adjusted model & 0 & $0.3(-0.3$ to 1.0$)$ & $0.4(-0.3$ to 1.0$)$ & $0.3(-0.4$ to 0.9$)$ & 0.892 \\
\hline Multivariate model* & 0 & $0.2(-0.4$ to 0.8$)$ & $0.2(-0.5$ to 0.8$)$ & $0.1(-0.5$ to 0.7$)$ & 0.936 \\
\hline
\end{tabular}

$\mathrm{FEV}_{1}$, forced expiratory volume in $1 \mathrm{~s} ; \mathrm{FVC}$, forced vital capacity.

*Adjusted for centre, ethnicity, age, smoking status, pack-years of cigarette smoking, environmental tobacco smoke, body mass index, occupation, educational level, census tract-based income, height, square of height and background air pollution level.

tp Values for trend based on quartiles scaled by the quartile medians.

higher traffic density. ${ }^{10} \mathrm{~A}$ cross-sectional Thai study reported that the $\mathrm{FEV}_{1}$ and partial expiratory flow volume in 78 police in Bangkok (with high traffic exposure) was much lower than in 68 police in a rural area. ${ }^{11}$ In a cross-sectional study of 4757 German women, living near a major road had a detrimental effect on lung function, ${ }^{12}$ and in a cross-sectional study of 1986 Tokyo residents, pulmonary function did not vary with distance to roads but automobile exhaust was associated with respiratory symptoms. ${ }^{14}$

We found clearer associations in women than in men. Our measures of traffic exposure, traffic density and distance to major roads were inversely associated with lung function only in women. Few studies have reported stratified analyses of air pollution health effects by sex, and the patterns are not conclusive. In children, several studies ${ }^{38} 40$ found stronger effects of air pollution on respiratory symptoms and lung function in girls than in boys. Conversely, in the Children's Health Study (CHS), the effect of traffic air pollution on lung development was stronger in boys than in girls. ${ }^{42}$ Gehring et al also found a stronger effect of traffic air pollution on respiratory symptoms in boys than in girls. ${ }^{43}$ In adults, studies in the USA and Switzerland found similar effects in both sexes, ${ }^{35} 4445$ whereas Abbey et al observed an association between lower lung function and long term exposure to particles only in men. ${ }^{46}$

Our finding of a stronger association of reduced lung function with greater traffic exposure in women is consistent with some studies ${ }^{47-49}$ showing that women experience a greater smoking related decline in lung function than men, but not others.50 Compared with men, women have slightly greater airway reactivity ${ }^{51}$ so dose-response relations may be detected more easily. In addition, the validity of the exposure may vary by sex and could partly explain the observed sex difference in our data. At visit 1, 35\% of women but only 17\% of men reported being home makers, unemployed or retired. Thus, women may, on average, have spent more time at home than men. While we cannot confirm this with our data, this has been reported in other studies. ${ }^{52}$ Our exposure assessment based on home address might therefore better reflect the true exposure level for women than for men.

We did not observe an effect of background air pollution on lung function. This is not surprising given that the ARIC study was not designed to examine air pollution and was limited to four communities. Furthermore, as these communities were not well supplied with air pollution monitors during the study period, little variation in air pollution within communities was captured by the available measurements.

Motor vehicle emissions, the principal source of ambient air pollution in most urban areas, are likely to vary substantially even within a given community. Research has documented differences in traffic related pollutants on a neighbourhood scale. ${ }^{53}$ The traditional exposure assessment relying on a small number of monitors might not therefore estimate individual

Table 5 Associations between distance to major roads and $\mathrm{FEV}_{1}, \mathrm{FVC}$ and $\mathrm{FEV}_{1} / \mathrm{FVC}$ ratio in ARIC participants (1987-9)

\begin{tabular}{|c|c|c|c|c|c|c|c|}
\hline & & \multicolumn{3}{|c|}{ Dichotomised at $150 \mathrm{~m}$} & \multicolumn{3}{|c|}{ Dichotomised at $100 \mathrm{~m}$} \\
\hline & & $\geqslant 150 \mathrm{~m}$ & $<150 \mathrm{~m}$ & $\mathrm{p}$ Value & $\geqslant 100 \mathrm{~m}$ & $<100 \mathrm{~m}$ & $p$ Value \\
\hline \multicolumn{8}{|l|}{ Women } \\
\hline \multirow[t]{2}{*}{$\mathrm{FEV}_{1}(\mathrm{ml})$} & Age adjusted model & 0 & $-29.5(-52.2$ to -6.9$)$ & 0.011 & 0 & $-17.4(-41.9$ to 7.1$)$ & 0.165 \\
\hline & Multivariate model ${ }^{*}$ & 0 & $-15.7(-34.4$ to 2.9$)$ & 0.099 & 0 & $-17.2(-37.5$ to 3.2$)$ & 0.098 \\
\hline \multirow[t]{2}{*}{$\mathrm{FVC}(\mathrm{ml})$} & Age adjusted model & 0 & $-33.2(-60.4$ to -5.9$)$ & 0.017 & 0 & $-10.2(-39.8$ to 19.3$)$ & 0.497 \\
\hline & Multivariate model ${ }^{*}$ & 0 & $-24.2(-46.2$ to -2.3$)$ & 0.030 & 0 & $-16.4(-40.3$ to 7.5$)$ & 0.178 \\
\hline \multirow{2}{*}{$\mathrm{FEV}_{1} / \mathrm{FVC}(\%)$} & Age adjusted model & 0 & $-0.1(-0.5$ to 0.2$)$ & 0.505 & 0 & $-0.3(-0.7$ to 0.0$)$ & 0.084 \\
\hline & Multivariate model ${ }^{*}$ & 0 & $0.1(-0.3$ to 0.4$)$ & 0.731 & 0 & $-0.2(-0.5$ to 0.2$)$ & 0.268 \\
\hline \multicolumn{8}{|l|}{ Men } \\
\hline \multirow{2}{*}{$\mathrm{FEV}_{1}(\mathrm{ml})$} & Age adjusted model & 0 & $-38.1(-76.7$ to 0.6$)$ & 0.054 & 0 & $-43.9(-85.9$ to -2.0$)$ & 0.040 \\
\hline & Multivariate model* & 0 & $-6.4(-38.1$ to 25.3$)$ & 0.693 & 0 & $-18.5(-53.2$ to 16.2$)$ & 0.295 \\
\hline \multirow[t]{2}{*}{$\mathrm{FVC}(\mathrm{ml})$} & Age adjusted model & 0 & $-17.0(-62.0$ to 28.0$)$ & 0.460 & 0 & $-27.7(-76.5$ to 21.1$)$ & 0.266 \\
\hline & Multivariate model* & 0 & $10.9(-24.7$ to 46.5$)$ & 0.548 & 0 & $-7.9(-46.8$ to 31.1$)$ & 0.692 \\
\hline \multirow[t]{2}{*}{$\mathrm{FEV}_{1} / \mathrm{FVC}(\%)$} & Age adjusted model & 0 & $-0.5(-0.9$ to 0.0$)$ & 0.058 & 0 & $-0.5(-1.0$ to 0.0$)$ & 0.052 \\
\hline & Multivariate model* & 0 & $-0.3(-0.7$ to 0.2$)$ & 0.214 & 0 & $-0.3(-0.7$ to 0.2$)$ & 0.249 \\
\hline
\end{tabular}

FEV 1 , forced expiratory volume in $1 \mathrm{~s}$; FVC, forced vital capacity.

*Adjusted for centre, ethnicity, age, smoking status, pack-years of cigarette smoking, environmental tobacco smoke, body mass index, occupation, educational level, census tractbased income, height, square of height and background air pollution level. 
exposure levels adequately. In early epidemiological studies of the health effects of traffic exposure, the self-reported proximity of the home address to major roads ${ }^{54}$ and selfreported road type and traffic density ${ }^{55}{ }^{56}$ were used. In contrast, we used objective measures of traffic related air pollution at residential addresses such as GIS based assessment of traffic density and distance to major roads.

The limitations of our analysis should be noted. Because the geocodes for participants' addresses at visits 1 and 2 (1987-92) were obtained from the TIGER file by Mapping Analytics, error could result from the use of older road network data. To assess this we randomly selected 100 participants from each of the ARIC communities and re-geocoded their residential addresses using the GDT software which incorporates a more recent road network database. Using these new geocodes, we re-calculated the traffic densities and distances to major roads and compared them with the original results. The two geocoding methods resulted in similar estimates for the distance to nearest major roads (data not shown). For traffic density, the two methods yielded quite concordant values for the Forsyth, Jackson and Minneapolis communities, but concordance was lower for Washington County. This might reflect a renaming of streets that occurred there. We therefore repeated our analyses excluding Washington County from our analysis. With the less precise exposure assessment in Washington County excluded, the associations of traffic exposure with $\mathrm{FEV}_{1}$ and FVC became modestly stronger despite the reduced sample size (tables All and Al2 in the online appendix available at http://thorax.bmj. com/supplemental). These additional analyses suggest that the association we observed is relatively robust to geocoding error.

We used a relatively simple proxy for traffic related air pollution (traffic density and distance to major roads) and did not attempt to model the concentrations of traffic related air pollutants or to validate our exposure assessment with measurements. Although recent data suggest stronger associations with stop-and-go traffic than moving traffic and with truck traffic compared with car traffic, ${ }^{1}$ like most studies we could not classify traffic by type. We did not consider the acute effect of traffic exposure on lung function; however, given evidence that the association between the daily ambient level of air pollution and daily means of lung function is smaller in magnitude than the association between the long-term level of ambient air pollution and average lung function, ${ }^{45}{ }^{57}$ we suspect that any bias introduced by not controlling for the acute effect of traffic exposure would be minimal.

We lacked assessment of traffic related air pollution on approximately $11.6 \%$ of subjects ( $10.0 \%$ of women and $13.5 \%$ of men) whose addresses could not be geocoded. This raises concern about potential selection bias. However, when we compared pulmonary function measurements and demographic characteristics in ARIC participants with and without geocoded addresses (table Al in the online appendix available at http:// thorax.bmj.com/supplemental), we did not find significant differences. It is therefore unlikely that the data missing for $10.0 \%$ of women would have created the observed associations. Our exposure assessment was limited to residential address and we did not have information on duration of residence or on home exposures to other sources of pollutants such as cooking or heating. However, it is reassuring that an earlier study of ARIC participants reported very high concordance between county and state of residence in past decades to that at visit $1,{ }^{58}$ and in a study based on a sub-cohort of ARIC participants, ${ }^{59}$ more than $60 \%$ of subjects had addresses at ages between 30 and 50 years that were assigned latitudes and longitudes almost identical to those associated with their visit 1 address.

As in any epidemiological study, residual confounding is possible. However, we adjusted for known and potential confounders including demographic characteristics, personal and neighbourhood level socioeconomic characteristics, cigarette smoking and background air pollution. The cross-sectional nature of our data, as well as initial non-response, is also a limitation of our data.

A major strength of our analysis is that it was based on a large community based cohort from four US communities. We also had an objective and quantitative respiratory outcomenamely, lung function. In addition, both exposure and outcome data were collected at the individual level together with extensive data on potential confounders. There is evidence that, in addition to individual level factors, the residential area or neighbourhood may have an additional effect on health. ${ }^{60}$ Therefore, in the current analysis we also adjusted for a community level measure of socioeconomic status to help account for confounding.

In summary, in the ARIC study, higher exposure to trafficas measured by traffic density and distance to roadways-was related to modestly reduced lung function in women. To our knowledge, this is the largest study of traffic exposure and pulmonary function to date. Our results add to growing evidence that chronic exposure to traffic related air pollution may adversely affect respiratory health.

\section{ACKNOWLEDGEMENTS}

The authors thank the staff and participants of the ARIC study for their important contributions. They also thank Joy Wood, Grace Chiu, Qing Peng, Tami Funk and Bryan Penfold for their assistance.

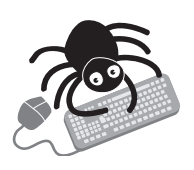

Further data are available in the appendix available online at http://thorax.bmj.com/supplemental.

\begin{abstract}
Authors' affiliations
Haidong Kan, Stephanie J London, Epidemiology Branch, National Institute of Environmental Health Sciences, National Institutes of Health, Department of Health and Human Services, Research Triangle Park, North Carolina, USA

Gerardo Heiss, Kathryn M Rose, Eric Whitsel, Department of Epidemiology, School of Public Health, University of North Carolina at Chapel Hill, North Carolina, USA

Eric Whitsel, Department of Medicine, School of Medicine, University of North Carolina at Chapel Hill, North Carolina, USA

Fred Lurmann, Sonoma Technology Inc, Petaluma, California, USA

The Atherosclerosis Risk in Communities Study is carried out as a collaborative study supported by National Heart, Lung, and Blood Institute contracts N01-HC-55015, N01-HC-55016, N01-HC-55018,

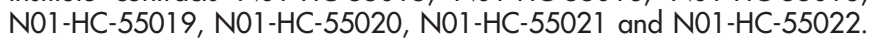
This work was also supported by Z01 ES043012 from the Intramural Research Program, National Institute of Environmental Health Science
\end{abstract} (NIEHS).

Competing interests: None.

\section{REFERENCES}

1 Ryan PH, LeMasters G, Biagini J, et al. Is it traffic type, volume, or distance? Wheezing in infants living near truck and bus traffic. J Allergy Clin Immunol $2005 ; 116: 279-84$.

2 Heinrich J, Topp R, Gehring U, et al. Traffic at residential address, respiratory health, and atopy in adults: the National German Health Survey 1998. Environ Res 2005;98:240-9.

3 Venn A, Yemaneberhan H, Lewis S, et al. Proximity of the home to roads and the risk of wheeze in an Ethiopian population. Occup Environ Med 2005:62:376-80.

4 Hwang BF, Lee YL, Lin YC, et al. Traffic related air pollution as a determinant of asthma among Taiwanese school children. Thorax 2005;60:467-73.

5 Migliaretti G, Cadum E, Migliore E, et al. Traffic air pollution and hospital admission for asthma: a case-control approach in a Turin (ltaly) population. Int Arch Occup Environ Health 2005;78:164-9.

6 Gauderman WJ, Avol E, Lurmann F, et al. Childhood asthma and exposure to traffic and nitrogen dioxide. Epidemiology 2005; 16:737-43. 
7 McConnell R, Berhane K, Yao L, et al. Traffic, susceptibility, and childhood asthma. Environ Health Perspect 2006; 114:766-72.

8 Evans RG, Webb K, Homan S, et al. Cross-sectional and longitudinal changes in pulmonary function associated with automobile pollution among bridge and tunnel officers. Am J Ind Med 1988;14:25-36.

9 Raaschou-Nielsen O, Nielsen ML, Gehl J. Traffic-related air pollution: exposure and health effects in Copenhagen street cleaners and cemetery workers. Arch Environ Health 1995;50:207-13.

10 Sekine K, Shima M, Nitta $Y$, et al. Long term effects of exposure to automobile exhaust on the pulmonary function of female adults in Tokyo, Japan. Occup Environ Med 2004;61:350-7.

11 Karita K, Yano E, Jinsart W, et al. Respiratory symptoms and pulmonary function among traffic police in Bangkok, Thailand. Arch Environ Health 2001;56:467-70

12 Schikowski T, Sugiri D, Ranft U, et al. Long-term air pollution exposure and living close to busy roads are associated with COPD in women. Respir Res 2005:6:152

13 Tollerud DJ, Weiss ST, Elting E, et al. The health effects of automobile exhaust. VI. Relationship of respiratory symptoms and pulmonary function in tunnel and turnpike workers. Arch Environ Health 1983:38:334-40.

14 Nakai S, Nitta H, Maeda K. Respiratory health associated with exposure to automobile exhaust. III. Results of a cross-sectional study in 1987, and repeated pulmonary function tests from 1987 to 1990 . Arch Environ Health 1999:54:26-33.

15 Smargiassi A, Baldwin M, Pilger C, et al. Small-scale spatial variability of particle concentrations and traffic levels in Montreal: a pilot study. Sci Total Environ 2005;338:243-51.

16 Braver $M$, Hoek $G$, van Vliet $P$, et al. Estimating long-term average particulate air pollution concentrations: application of traffic indicators and geographic information systems. Epidemiology 2003;14:228-39.

17 Hoek G, Brunekreef B, Goldbohm S, et al. Association between mortality and indicators of traffic-related air pollution in the Netherlands: a cohort study. Lancet 2002;360:1203-9.

18 ARIC Investigators. The Atherosclerosis Risk in Communities (ARIC) Study: design and objectives. Am J Epidemiol 1989;129:687-702.

19 National Heart Lung and Blood Institute. Atherosclerosis Risk in Communities (ARIC) Study. Operations manual no. 12. Quality assurance and quality control, version 1.0. Chapel Hill, North Carolina: ARIC Coordinating Center, School of Public Health, University of North Carolina, 1989.

20 National Heart Lung and Blood Institute. Atherosclerosis Risk in Communities (ARIC) Study. Manuals of operation: No. 2, cohort component procedures; No. 4, pulmonary function assessment; No. 6, ultrasound assessment; No. 7, blood collection and processing; No. 8, lipid and lipoprotein determinations; No. 9, hemostasis determinations; No. 10, clinical chemistry determinations; No. 12, quality assurance. Chapel Hill, North Carolina: ARIC Coordinating Center, University of North Carolina, 1987.

21 Polzin SE. The case for moderate growth in vehicle miles of travel: a critical juncture in U.S. travel behavior trends. Washington, DC: US Department of Transportation, 2006

22 Hoffmann B, Moebus S, Stang A, et al. Residence close to high traffic and prevalence of coronary heart disease. Eur Heart J 2006;27:2696-702.

23 Venn AJ, Lewis SA, Cooper M, et al. Living near a main road and the risk of wheezing illness in children. Am J Respir Crit Care Med 2001;164:2177-80.

24 Wilkinson P, Elliott P, Grundy C, et al. Case-control study of hospital admission with asthma in children aged 5-14 years: relation with road traffic in north west London. Thorax 1999;54:1070-4.

25 Geronimus AT, Bound J. Use of census-based aggregate variables to proxy for socioeconomic group: evidence from national samples. Am J Epidemiol 1998;148:475-86

26 US Bureau of the Census. Summary Tape File 3 on CD-Rom Technical Documentation. Washington, DC: US Department of Commerce, Economics and Statistics, 1992.

27 Cole TJ. Linear and proportional regression models in the prediction of ventilatory function. J R Stat Soc Ser A 1975;138:297-324.

28 Hoek G, Fischer P, Van Den Brandt P, et al. Estimation of long-term average exposure to outdoor air pollution for a cohort study on mortality. J Expo Anal Environ Epidemiol 2001;11:459-69.

29 Sunyer J. Urban air pollution and chronic obstructive pulmonary disease: a review. Eur Respir J 2001;17:1024-33.

30 Department of Health and Human Services. The health consequences of smoking: a report of the Surgeon General. Rockville, Maryland: Department of Health and Human Services, Public Health Service, Office on Smoking and Health, 2004.

31 Eisner MD. Environmental tobacco smoke exposure and pulmonary function among adults in NHANES III: impact on the general population and adults with current asthma. Environ Health Perspect 2002;110:765-70.
32 Calderon-Garciduenas L, Mora-Tiscareno A, Fordham LA, et al. Respiratory damage in children exposed to urban pollution. Pediatr Pulmonol 2003;36:148-61.

33 Raizenne M, Neas LM, Damokosh Al, et al. Health effects of acid aerosols on North American children: pulmonary function. Environ Health Perspect 1996;104:506-14.

34 Korrick SA, Neas LM, Dockery DW, et al. Effects of ozone and other pollutants on the pulmonary function of adult hikers. Environ Health Perspect 1998;106:93-9.

35 Chestnut LG, Schwartz J, Savitz DA, et al. Pulmonary function and ambient particulate matter: epidemiological evidence from NHANES I. Arch Environ Health 1991;46:135-44.

36 Petronella S, Thaller E, Hochman D, et al. Gulf Coast study of urban air pollution and respiratory function (surf). Epidemiology 2004;15:S44.

37 Buffels J, Degryse J, Heyrman J, et al. Office spirometry significantly improves early detection of COPD in general practice: the DIDASCO Study. Chest 2004; 125:1394-9.

38 Brunekreef B, Janssen NA, de Hartog J, et al. Air pollution from truck traffic and lung function in children living near motorways. Epidemiology 1997;8:298-303.

39 Fritz GJ, Herbarth O. Pulmonary function and urban air pollution in preschool children. Int J Hyg Environ Health 2001;203:235-44.

40 van Vliet $\mathbf{P}$, Knape $M$, de Hartog J, et al. Motor vehicle exhaust and chronic respiratory symptoms in children living near freeways. Environ Res 1997:74:122-32.

41 Pershagen G, Rylander E, Norberg S, et al. Air pollution involving nitrogen dioxide exposure and wheezing bronchitis in children. Int J Epidemiol 1995;24:1147-53.

42 Gauderman WJ, Vora H, McConnell R, et al. Effect of exposure to traffic on lung development from 10 to 18 years of age: a cohort study. Lancet 2007;369:571-7

43 Gehring U, Cyrys J, Sedlmeir G, et al. Traffic-related air pollution and respiratory health during the first 2 yrs of life. Eur Respir J 2002;19:690-8.

44 Schwartz J. Lung function and chronic exposure to air pollution: a cross-sectional analysis of NHANES II. Environ Res 1989:50:309-21.

45 Ackermann-Liebrich U, Leuenberger P, Schwartz J, et al. Lung function and long term exposure to air pollutants in Switzerland. Study on Air Pollution and Lung Diseases in Adults (SAPALDIA) Team. Am J Respir Crit Care Med 1997;155:122-9.

46 Abbey DE, Burchette RJ, Knutsen SF, et al. Long-term particulate and other air pollutants and lung function in nonsmokers. Am J Respir Crit Care Med 1998;158:289-98.

47 Downs SH, Brandli O, Zellweger JP, et al. Accelerated decline in lung function in smoking women with airway obstruction: SAPALDIA 2 cohort study. Respir Res 2005;6:45.

48 Langhammer A, Johnsen R, Gulsvik A, et al. Sex differences in lung vulnerability to tobacco smoking. Eur Respir J 2003;21:1017-23.

49 Xu X, Li B, Wang L. Gender difference in smoking effects on adult pulmonary function. Eur Respir J 1994;7:477-83.

50 Vollmer WM, Enright PL, Pedula KL, et al. Race and gender differences in the effects of smoking on lung function. Chest 2000;117:764-72.

51 Yunginger JW, Reed CE, O'Connell EJ, et al. A community-based study of the epidemiology of asthma. Incidence rates, 1964-1983. Am Rev Respir Dis 1992;146:888-94.

52 Kwan MP, Lee J. Geovisualization of human activity patterns using 3D GIS: a time-geographic approach. In: Goodchild MF, Janelle DG, eds. Spatially integrated social science: examples in best practice. New York: Oxford University Press, 2004:48-66.

53 Roorda-Knape MC, Janssen N, de Hartog J, et al. Air pollution from traffic in city districts near major motorways. Atmos Environ 1998;32:1921-30.

54 Garshick E, Laden F, Hart JE, et al. Residence near a major road and respiratory symptoms in U.S. Veterans. Epidemiology 2003;14:728-36.

55 Langholz B, Ebi KL, Thomas DC, et al. Traffic density and the risk of childhood leukemia in a Los Angeles case-control study. Ann Epidemiol 2002;12:482-7.

56 Wilhelm M, Ritz B. Residential proximity to traffic and adverse birth outcomes in Los Angeles county, California, 1994-1996. Environ Health Perspect 2003;111:207-16.

57 Schindler C, Kunzli N, Bongard JP, et al. Short-term variation in air pollution and in average lung function among never-smokers. The Swiss Study on Air Pollution and Lung Diseases in Adults (SAPALDIA). Am J Respir Crit Care Med $2001 ; 163: 356-61$.

58 Rose KM, Wood JL, Knowles S, et al. Historical measures of social context in life course studies: retrospective linkage of addresses to decennial censuses. Int J Health Geogr 2004;3:27.

59 Anon. Life Course Socioeconomic Status, Social Context and Cardiovascular Disease (LC-SES) Study, http://www.lifecourseepi.info.

60 Marmot M. Inequalities in health. N Engl J Med 2001;345:134-6.

\section{Save your favourite articles and useful searches}

Use the "My folders" feature to save and organise articles you want to return to quickly-saving space on your hard drive. You can also save searches, which will save you time. You will only need to register once for this service, which can be used for this journal or all BMJ Journals, including the BMJ. 